\title{
Functional treatment for fractures to the base of the 5th metatarsal - influence of fracture location and fracture characteristics
}

\author{
Sebastian Felix Baumbach, Wolf Christian Prall, Michael Kramer, Mareen Braunstein, Wolfgang Böcker
} and Hans Polzer

\begin{abstract}
Background: Fractures to the base of the fifth metatarsal are common, but their treatment remains controversial. Especially for Lawrence and Botte (L\&B) type II fractures, there is conflicting evidence and consequently no consensus. Further, many authors consider displacement, articular involvement, and number of fragments an indication for surgery, although evidence is missing. The aim of this study was to evaluate the outcome of functional treatment for all L\&B type I and II fractures. Of special interest were the influence of (1) the fracture location (L\&B type I vs. II) and (2) the fracture characteristics (displacement, intra-articular involvement, communition) on the subjective outcome.
\end{abstract}

Methods: Retrospective registry study with a prospective follow-up. Patients with an acute, isolated, epi-metaphyseal fracture to the fifth metatarsal bone (L\&B type I and II) treated by full weightbearing with a minimum follow-up of 6 months were included. Fracture location (L\&B type I and II) and characteristics (displacement $<2 \mathrm{~mm}$ or $>2 \mathrm{~mm}$, intra-articular involvement, and number of fragments) were assessed. Outcome parameters were return to work, return to sports, VAS-FA, and SF-12. The influence of the fracture (1) location and (2)-characteristics on these parameters was tested.

Results: Thirty-nine patients ( $40 \pm 15$ years, $56 \%$ female) were enrolled with a mean follow-up of $22 \pm 10$ months. L\&B type I fractures occurred in 59\%, type II in 41\%. Thirty-one percent of all fractures were dislocated, $74 \%$ intra-articular, and $41 \%$ multi-fragmentary. Patients returned to work after $17 \pm 12$ days, to sports after $53 \pm 22$ days. The VAS-FA score at the final follow-up was $96 \pm 4$, SF-12 PCS score $57 \pm 5$ and MCS score $51 \pm 8$. No complications were reported, no patient required surgery. None of the assessed outcome parameters differed significantly between (1) the different fracture locations (L\&B type I vs. II) or (2) the different fracture characteristics (displacement, intra-articular involvement, and number of fragments).

Conclusions: (1) Both, L\&B I and II fractures featured excellent results with immediate full weightbearing. Consequently, L\&B type I and II fractures should be summarized as epi-metaphyseal fractures. (2) Fracture displacement, articular involvement, and number of fragments did not influence the outcome. Therefore, functional treatment should be recommended for all epi-metaphyseal fractures.

Keywords: Fifth metatarsal fracture, Lawrence and Botte, Functional treatment, Fracture characteristics, Outcome

* Correspondence: Hans.Polzer@med.uni-muenchen.de

Department of Trauma Surgery, Munich University Hospital, LMU,

Nussbaumstr. 20, 80336 Munich, Germany

(c) The Author(s). 2017 Open Access This article is distributed under the terms of the Creative Commons Attribution 4.0 International License (http://creativecommons.org/licenses/by/4.0/), which permits unrestricted use, distribution, and reproduction in any medium, provided you give appropriate credit to the original author(s) and the source, provide a link to the Creative Commons license, and indicate if changes were made. The Creative Commons Public Domain Dedication waiver (http://creativecommons.org/publicdomain/zero/1.0/) applies to the data made available in this article, unless otherwise stated. 


\section{Background}

Treatment recommendations for fractures to the base of the fifth metatarsal (MTV) are still a matter of debate. Possible causes are missing evidence, various fracture classifications, and diverging definitions for the term "Jones fracture" [1-4]. The most widely accepted classification was published by Lawrence and Botte [3] (L\&B) in 1993. They differentiated tuberosity avulsion fractures (type I), Jones' fractures (type II) and diaphyseal stress fractures (type III) (Fig. 1). A recent systematic literature review [5] evaluated the validity of the classification system and treatment recommendations by Lawrence and Botte. Overall the level of evidence available was moderate. Based on this evidence a treatment-oriented adaptation of the L\&B classification was concluded. In summary, L\&B type I and II fractures should not be differentiated but be summarized as epi-metaphyseal

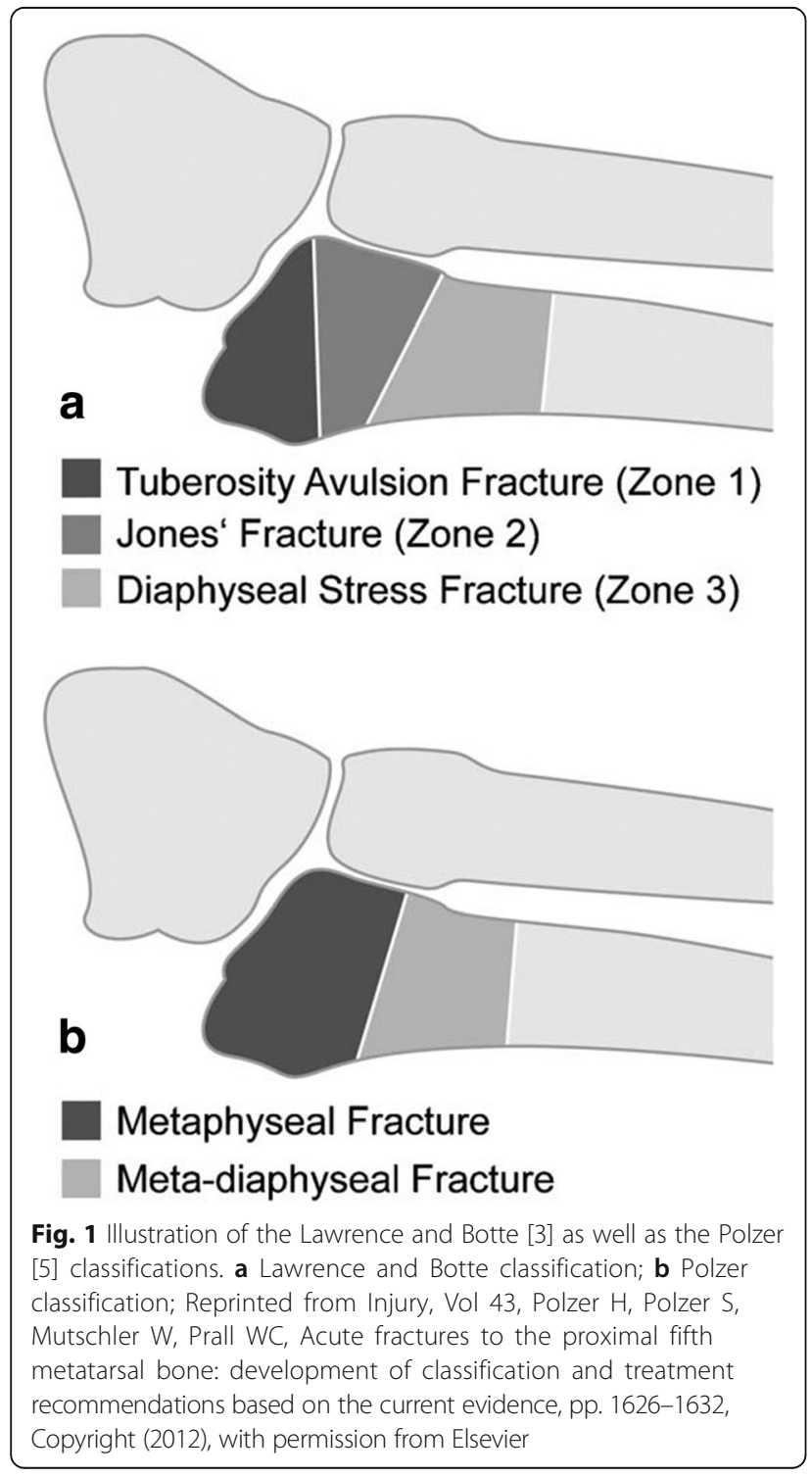

fractures, as both apparently heal well when treated functionally. Although these recommendations are based on strong evidence for L\&B type I fractures, only little evidence is available for $L \& B$ type II fractures. In contrast, strong evidence is available in favour of surgical treatment for L\&B type III fractures (meta-diaphyseal fractures). Furthermore, it remains largely unknown, whether fracture characteristics, i.e. displacement, articular involvement, number of fragments, negatively influence the outcome of functional treatment and therefore require surgery.

Therefore, the aim of this study was to evaluate the outcome of functional treatment for all L\&B type I and II fractures. The following two hypotheses were tested:

(1) The fracture location (L\&B type I vs. II) does influence the outcome.

(2) The fracture characteristics (displacement, intraarticular involvement, communition) affect the outcome.

\section{Methods \\ Study design}

Retrospective registry study with a prospective follow up. The study was approved by the local ethic committee (\# 541-14).

\section{Patient selection}

The study was conducted by the Division of Foot and Ankle Surgery at the University Hospital of Munich (LMU). Patients suffering an isolated epi-metaphyseal fracture to the proximal fifth metatarsal bone (L\&B type I or II, Fig. 1) between Jan. 1st 2012 and Oct. 1st 2014 were identified retrospectively using the clinical and radiographic database of the Munich University Hospital. The clinical database was searched for patients diagnosed with a metatarsal fracture (ICD-10 Vs. 2013: S92.3). The radiographic database was searched for the terms: Metatarsal AND fracture AND (5 OR V) OR Jones. All fractures were reviewed independently by two investigators (SFB, HP). First, isolated fractures to the fifth metatarsal were identified. Then, fractures located distal to the fourth-fifth intermetatarsal articulation were excluded. All remaining fractures were located at the base of the fifth metatarsal (L\&B type I and II) not extending beyond the distal end of the fourth-fifth intermetatarsal articulation (L\&B type III). These patients were invited for a final follow-up visit. Only patients meeting all inclusion criteria, including the final followup visit, were enrolled. Eligibility criteria are stated in detail in Table 1.

The results of the search strategy are outlined in Fig. 2. The database search identified 315 fractures affecting the fifth metatarsal bone. One hundred thirty were 
Table 1 Inclusion and exclusion criteria

\begin{tabular}{ll}
\hline Inclusion criteria & Exclusion criteria \\
\hline Age $\geq 18$ years & Age $<18$ years \\
Isolated, traumatic, epi-metaphyseal & Meta-diaphyseal- (L\&B type III), \\
fractures to the proximal fifth & shaft-, and distal fractures to the \\
metatarsal (L\&B type I \& II) & fifth metatarsal \\
Follow-up of at least 6 month & Any further injuries \\
& Non-traumatic or any pathological \\
& fractures \\
& Time to treatment $>6$ weeks \\
& Missing initial radiographs \\
\hline
\end{tabular}

located at the proximal end of the fifth metatarsal. In total 95 fractures met the inclusion criteria. Thirty-nine patients (41\%) completed the final follow-up and were therefore included in the final analysis. Their mean age was $40 \pm 15$ years, $56 \%$ were female.

\section{Treatment regimen}

Patients with acute fractures to the proximal fifth metatarsal first presented to the emergency department and were then transferred to the outpatient clinic of the Division of Foot and Ankle Surgery. After informed consent, functional treatment was initiated. The treatment recommendations have been described in detail earlier [5]. In brief, all patients were instructed to wear shoes with a stiff sole and conduct weightbearing as tolerated. In case pain limited immediate full weightbearing, partial weightbearing on crutches was conducted. Full weightbearing was recommended as soon as possible, the latest

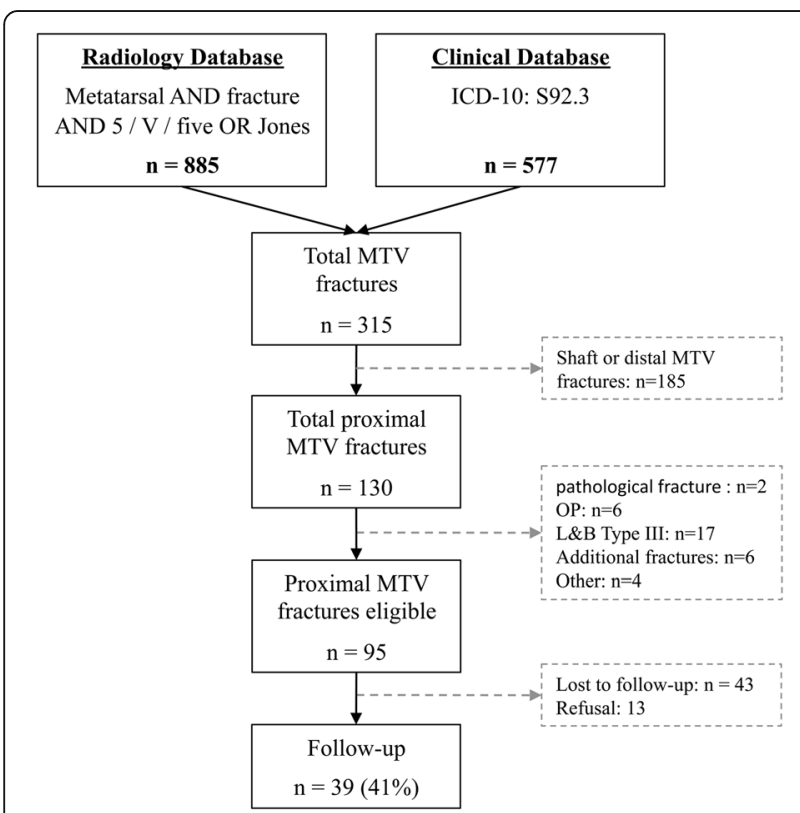

Fig. 2 Flow chart depicting the patient selection. MTV: Fifth metatarsal; $\mathrm{n}=$ Number; L\&B: Lawrence and Botte; OP: Operation after 2 weeks. In case of severe swelling the foot was immobilized using a walker or a short leg cast for a maximum of 2 weeks. Return to work and sports was encouraged as soon as possible. Radiographic follow-up was performed in case of prolonged symptoms of more than 6 weeks only. If symptoms subsided within 6 weeks, no radiographic follow-up was performed. This treatment regimen was conducted for all epi-metaphyseal fractures (L\&B type I \& II), not extending beyond the distal end of fourth-fifth intermetatarsal articulation (L\&B type III), regardless of the number of fragments, displacement and intraarticular involvement.

\section{Data collection}

Data were collected retrospectively based on patient records and prospectively based on a follow-up visit or phone interview. Table 2 lists the variables collected. Fracture classification and characteristics were assessed on the initial radiographs by two independent investigators (SFB, HP). Disagreement was resolved by discussion. Fractures were first classified per Lawrence and Botte type I or II [3]. Then, the following fracture characteristics were assessed: Displacement (none, $\leq 2 \mathrm{~mm}$, $>2 \mathrm{~mm}$ ), intra-articular involvement (binary), and number of fragments (two- or multiple). Fractures were classified intra-articular if the articulation between the metatarsal and cuboid bone was affected. Finally, if available, radiographic follow-ups after 6 weeks were evaluated. Patient records were screened for complications as well as return to work and sports. In order to evaluate the mid-term results, patient rated outcome measures were assessed at the final follow-up visit at least 6 months after the trauma.

\section{Outcome variables}

The primary outcome parameter was return to work. Secondary outcome parameters were return to sports, the Visual Analog Scale Foot and Ankle (VAS-FA) [6] and the 12-item short-form (SF-12v2). The VAS-FA was evaluated using the developers' analysis instrument [6]. The VAS-FA is a validated, subjective, VAS based foot and ankle outcome score. It comprises of 20 items,

Table 2 Variables assessed based on the patient records and follow-up

\begin{tabular}{ll}
\hline $\begin{array}{l}\text { Patient } \\
\text { records }\end{array}$ & Age, Sex \\
& Fracture location: Lawrence and Botte type I and II [3] \\
& Fracture characteristics: Number of fragments, displacement, \\
& articular involvement \\
& Complications \\
& Return to work \\
& Return to sports \\
& Radiographic follow-up (when available) \\
& VAS-FA [6] \\
Follow-up & SF-12v2 \\
\hline
\end{tabular}


grouped into three categories (function, pain, other complaints) $[7,8]$. Score values for the overall and subgroup scores range between 0 and 100 points, with higher scores indicating a better outcome. The SF-12 score was analysed using the manufactures analytic tool-box (license number QM027870). The SF-12v2 is a short version of the SF-36 Health Survey, measuring eight domains. These are consolidated into two meta-scores: The Mental Component Summary (MCS) and the Physical Component Summary (PCS). The MCS and PCS scores range between 0 to 100 , with a score of 50 being representative for a sample population.

\section{Data analysis and statistics}

Data analysis was conducted to assess the influence of (1) the fracture location (L\&B type I vs. II) and (2) the fracture characteristics (displacement, intra-articular involvement, and number of fragments) on the outcome variables outlined above. Statistics applied were standard descriptive statistics, independent T-tests, and ChiSquare-test, were appropriate. Furthermore, the influence of the fracture classification and characteristics (independent variables) on the outcome parameters (dependent variable) were assessed using a linear regression model (Enter Method). Results are indicated as means \pm standard deviation (SD). Due to multiple testing, an alpha-level correction (Bonferroni) was conducted $(p<0.007)$. Statistics were computed using SPSS Vs. 21 (IBM Company).

\section{Results}

Fracture classification and characteristics

The left proximal MTV was fractured in $49 \%$. Lawrence and Botte type I fractures occurred in $59 \%$ of the patients. Out of all fractures, 31\% were dislocated (>2 mm), 74\% intra-articular, and $41 \%$ multi-fragmentary (Table 3). Intra-articular fractures (fifth metatarso-cuboid joint) occurred significantly more often in L\&B type I compared to type II fractures $(p=0.004)$. No significant differences were observed for displacement or number of fragments between both fracture types. No significant age, side, or gender differences were found for any of these parameters.

Table 3 Fracture characteristics per L\&B Zone I and II fractures

\begin{tabular}{lllll}
\hline & Number & Dislocated & Intra-articular & Multi-fragmentary \\
\hline Total & 39 & $31 \%$ & $74 \%$ & $41 \%$ \\
L\&B type I & $23(59 \%)$ & $26 \%$ & $91 \%$ & $39 \%$ \\
L\&B type II & $16(41 \%)$ & $38 \%$ & $50 \%$ & $44 \%$ \\
$p$-value & & 0.447 & 0.004 & 0.773 \\
\hline
\end{tabular}

L\&B Lawrence and Botte

\section{Treatment details}

All patients were treated according to the regimen outlined above. Twenty-eight percent of patients bore weight fully in a hard-soled shoe immediately. The remaining patients were temporarily immobilized for a maximum of 2 weeks (cast: $8 \%$, walking boot: $54 \%$, short walking boot: 10\%). The mean number of follow-up visits at our outpatient clinic was $1.3 \pm 1.6$ (range: $0-6$ ). This figure does not include the final follow up visit, which was conducted to assess the mid-term results.

\section{Outcome}

The mean follow-up was $22 \pm 10$ month (6-40 month). The patients returned to work after $17 \pm 12$ days (range: 0-56 days), and to previous sports levels after $53 \pm$ 22 days (range: 21-100) on average. At final follow-up, the overall VAS-FA score was $96 \pm 4$, the subscale pain $95 \pm 7$, and the subscale function $97 \pm 4$. The mean SF12 PCS score was $57 \pm 5$ and the MCS score $51 \pm 8$. No complications were reported, no patient required surgery. Seven patients (18\%) suffered symptoms after 6 weeks. Only these patients received a radiographic follow-up. All these follow-up radiographs were unsuspicious, showing bony union in all cases. Patients receiving follow-up radiographs did not differ in any respect (fracture location, -characteristics, or outcome variables) to those with no follow-up radiographs. No complications were identified.

\section{Influence of fracture location}

The above outlined outcome variables (return to work, return to sports, VAS-FA, SF-12) were analysed separately for each fracture location (L\&B type I and II). An independent students t-test revealed no significant difference for these outcome variables between the two fracture locations (Table 4). The linear regression model also proofed no significant influence of the fracture location on any of the outcome parameters.

\section{Influence of fracture characteristics}

A similar analysis was conducted to assess the influence of the fracture characteristics (displacement, intraarticular involvement, and number of fragments) on all outcome variables (Table 5). None of the fracture characteristics individually had a significant influence on any of the outcome parameters. Similar, the linear regression model showed no significant effect of the fracture characteristics on the outcome scores.

\section{Discussion}

Whereas there is a broad consensus on functional treatment for non-displaced L\&B type I fractures, limited evidence is available for the best treatment for L\&B type II fractures [9-17]. Today, few studies report promising 
Table 4 Fracture type and outcome variables at final follow-up

\begin{tabular}{|c|c|c|c|c|c|c|c|}
\hline & Return to work [d] & Return to sports $[\mathrm{d}]$ & VAS Overall & VAS Pain & VAS Function & SF-12 PCS & SF-12 MCS \\
\hline Total & $17 \pm 12$ & $53 \pm 22$ & $96 \pm 4$ & $95 \pm 7$ & $97 \pm 4$ & $57 \pm 5$ & $51 \pm 8$ \\
\hline L\&B type I & $15 \pm 10$ & $47 \pm 19$ & $97 \pm 3$ & $96 \pm 6$ & $98 \pm 3$ & $58 \pm 3$ & $51 \pm 7$ \\
\hline L\&B type II & $20 \pm 15$ & $63 \pm 25$ & $95 \pm 4$ & $92 \pm 7$ & $96 \pm 5$ & $55 \pm 7$ & $51 \pm 9$ \\
\hline p-value & 0.194 & 0.040 & 0.098 & 0.051 & 0.069 & 0.133 & 0.915 \\
\hline
\end{tabular}

$d$ days, L\&B Lawrence and Botte [3], VAS VAS-FA [6], SF-12 PCS SF-12 Physical Health Composite Scores, SF-12 MCS Mental Health Composite Scores

results following functional treatment while other authors argue for operative treatment [18-21]. A major reason for these conflicting recommendations is the inconsistent use of the term "Jones fracture" for both L\&B type II and III fractures [22-24]. An example for the confusion resulting from this lack of definition is the systematic review by Roche et al. [25], analysing the outcome of "Jones fractures" in 26 studies. When looking at these studies in detail, the great majority analysed L\&B type III fractures. Some did not clearly define the fracture types and only one study clearly included L\&B type II fractures. In consequence, the actual treatment recommendation for type II fractures remains unclear.

In the herein presented study, early functional treatment of all L\&B type I and II fractures lead to excellent results (Tbl. 4). Both, return to work and sports were comparable to previous studies including L\&B type I fractures only $[12,14,16,26]$. The mean foot specific outcome score (VAS-FA) for all fractures was similar to healthy individuals $(94.5 \pm 8.2$ Points) [27]. The participants' quality of life scores (SF-12: PCS and MCS) were slightly higher than the populations' average. Finally, our treatment regimen did not result in any complications or conversion of treatment. When comparing L\&B type I and II fractures no significant differences could be detected for any outcome parameter within a follow-up of $22 \pm 10$ months.

The few studies available for type II fractures demonstrated comparable results to the herein presented findings. Still they are inherent of shortcomings that need to be discussed. Bigsby et al. [19] reported on the outcome of 62 type I and 26 type II fractures. No differences were found for the Foot Function Index (FFI) and the Short Form 36 between type I and II fractures. Unfortunately, no standardized treatment regimen was applied. Konkel et al. [28] treated 35 type I and 10 type II fractures nonoperatively. Treatment varied from no treatment to immobilization in a short leg cast. In average patients required 3.5 months to resume full duty. The orthesis, cast or shoe was applied for a minimum of 6 weeks. This long immobilization might have contributed to the prolonged time of recovery. Nevertheless, $100 \%$ of the patients were satisfied with the result. Van Aaken et al. [18] applied functional treatment for 15 type I and 8 type II fractures with an elastic dressing. The mean time to return to work was 21 days for patients with type I fractures compared to surprisingly 4 days for patients with type II fractures. Taken together, type II fractures can be treated functionally with an excellent clinical outcome, comparable to L\&B type I fractures.

Further, many authors postulate that displaced $(>2 \mathrm{~mm})$, multifragmentary, or intra-articular fractures necessitate operative treatment. Almost all of these recommendations are solely based on the authors' opinion, but not on evidence [3, 10, 29-33]. Therefore, the second aim of this study was to evaluate the influence of these aspects on the outcome of functionally treated L\&B type I and II

Table 5 Fracture characteristics and outcome parameters at final follow-up

\begin{tabular}{|c|c|c|c|c|c|c|c|}
\hline & Return to work [d] & Return to sports [d] & VAS Overall & VAS Pain & VAS Function & SF-12 PCS & SF-12 MCS \\
\hline Total & $17 \pm 12$ & $53 \pm 22$ & $96 \pm 4$ & $95 \pm 7$ & $97 \pm 4$ & $57 \pm 5$ & $51 \pm 8$ \\
\hline Non-dislocated & $18 \pm 12$ & $51 \pm 23$ & $96 \pm 4$ & $95 \pm 7$ & $97 \pm 4$ & $56 \pm 6$ & $51 \pm 7$ \\
\hline Dislocated & $15 \pm 12$ & $57 \pm 22$ & $97 \pm 3$ & $95 \pm 7$ & $98 \pm 3$ & $58 \pm 3$ & $51 \pm 9$ \\
\hline p-value & 0.502 & 0.536 & 0.323 & 0.987 & 0.439 & 0.220 & 0.876 \\
\hline Extra-articular & $17 \pm 13$ & $60 \pm 28$ & $95 \pm 5$ & $92 \pm 9$ & $96 \pm 5$ & $56 \pm 6$ & $50 \pm 11$ \\
\hline Intra-articular & $17 \pm 12$ & $51 \pm 20$ & $97 \pm 3$ & $96 \pm 6$ & $98 \pm 4$ & $57 \pm 5$ & $52 \pm 6$ \\
\hline$p$-value & 0.970 & 0.343 & 0.340 & 0.202 & 0.275 & 0.546 & 0.604 \\
\hline Two fragments & $16 \pm 10$ & $52 \pm 25$ & $96 \pm 4$ & $95 \pm 7$ & $97 \pm 4$ & $56 \pm 4$ & $53 \pm 8$ \\
\hline Multi fragmentary & $18 \pm 15$ & $54 \pm 20$ & $96 \pm 4$ & $95 \pm 7$ & $97 \pm 4$ & $57 \pm 7$ & $49 \pm 8$ \\
\hline$p$-value & 0.682 & 0.833 & 0.991 & 0.971 & 0.835 & 0.760 & 0.214 \\
\hline
\end{tabular}

$d$ days, VAS VAS-FA [6], SF-12 PCS SF-12 Physical Health Composite Scores, SF-12 MCS SF-12 Mental Health Composite Scores 
fractures. None of the fracture characteristics analysed, namely fracture displacement greater $2 \mathrm{~mm}$, articular involvement, or comminution, affected any of the outcome parameters assessed.

To the authors' knowledge, only two studies report data regarding the impact of intra-articular involvement and displacement on the clinical outcome [16, 17]. Egol et al. [16] treated L\&B type I fractures by immediate weightbearing as tolerated. Out of these, $50 \%$ were intraarticular and $32 \%$ displaced $(>2 \mathrm{~mm})$. The average time to return to work was 22 days. Comparing intra- to extra-articular fractures and non-displaced to displaced fractures, no significant differences could be observed for any of the outcome parameters (SMFA pain, VAS). Tahririan et al. [17] treated 143 patients with a fracture to the base of the fifth metatarsal (L\&B type I, II, III) with a short leg cast for 6 weeks. The average AOFAS score after 20 weeks for all fractures was 93 with a $95 \%$ confidence interval of 92-94. The multivariate analysis revealed that displacement, patient weight, type III fractures, diabetes and female gender were associated with a poorer AOFAS. One should keep in mind, that the AOFAS score, the only outcome parameter assessed, has been proven to be poorly valid and the minimal important clinical difference of this score is unknown [34]. Moreover, the average AOFAS in this study was extremely high with a remarkably narrow CI suggesting an excellent outcome for all fractures. Finally, the results of the statistical analysis are not comprehensible, as the authors did not present any data in detail. All in all, the data presented in our study argue for functional treatment of all L\&B type I and II fractures, independent of displacement, articular involvement, or comminution.

Several limitations and strengths have to be discussed. First, the most pronounced limitation is the initial retrospective data assessment. Second, the final follow-up rate is limited to $41 \%$. Consequently, it is unclear what happened to the patients lost to follow up, whether they received surgery elsewhere, suffered inferior clinical results or were in line with the patients included in this study. Still, this follow-up rate is compare to previous studies [35-37]. Third, patient specific factors such as intrinsic bone disorders or metabolic disorders were not assessed. Fourth, despite a mean follow-up of almost 2 years, refractures have been reported to occur even after that time range [38]. Still, most recent studies report low re-fracture rates in operatively treated patients initially suffering a stress fracture (L\&B type III) [39] or athletes $[21,38,40]$. The risk for re-fracture after conservative treatment for L\&B type I and II fractures remains unknown. A final limitation could be, a missing radiographic follow up for all patients. In accordance with literature, radiographic follow up was only conducted in case of prolonged symptoms of more than 6 weeks. In these patients, no non-union was observed. Still, asymptomatic non-unions could have been missed. As an asymptomatic non-union does not require any further treatment the authors would not consider this a complication. Therefore, we are convinced, that the missing radiographic follow-up of asymptomatic patients should not be considered a limitation. Contrariwise, this regime drastically reduces the number of follow-up visits.

Strengths of this study were the use of two validated patient rated outcome measures, one specific for foot and ankle disorders, the other a commonly used quality of life score [6, 27]. Furthermore, the fracture characteristics were assessed by two independent investigators and a mean, prospective follow up of almost 2 years was reached. Finally, a detailed workup of various factors possibly influencing the results was presented.

\section{Conclusions}

In conclusion, functional treatment leads to excellent clinical results for both, L\&B type I and type II fractures. (1) As both fracture locations did not differ for outcome, they should not be delineated, but rather be summarized as epi-metaphyseal. (2) Fracture displacement greater $2 \mathrm{~mm}$, intra-articular involvement, and comminution did not affect the outcome. Therefore, functional treatment should be applied to all epi-metaphyseal fractures, even when displaced, intra-articular or comminuted.

\section{Abbreviations \\ \%: Percent; <: Smaller than; >: Greater than; \pm : Plus / minus; $\leq$ : Smaller or equal; d: Days; Fig.: Fig.i ICD-10: International Statistical Classification of Diseases and Related Health Problems by the World Health Organization; L\&B: Lawrence and Botte; MCS: Mental component summary; mm: Millimetre; MTV: Fifth metatarsal bone; p: $p$-value; PCS: Physical component summary; SD: Standard deviation; SF-12: 12-item short-form of the SF-36 Health Survey; VAS-FA: Visual analog scale foot and ankle; Vs.: Versus}

\section{Acknowledgements}

Not applicable.

\section{Funding}

The study has not received any funding.

\section{Availability of data and materials}

The datasets used and/or analysed during the current study are available from the corresponding author on reasonable request.

\section{Authors' contributions}

SFB was responsible for ethics approval, data analysis / interpretation and paper preparation. WCP was involved in the initial study idea, data interpretation and manuscript preparation. MK conducted the data collection, follow-up visits and preliminary data analysis. MB was involved in the process of ethics approval, data collection and interpretation. WB was one of the study instigators, was involved in data interpretation and manuscript preparation. HP had the idea for the study, outlined the ethics proposal, conducted final data analysis and interpretation and was responsible for the final manuscript. All authors have read and approved the final version of the manuscript.

\section{Authors' information}

HP and WCP are the authors of the systematic literature review [5] evaluating the validity of the classification system and treatment recommendations by Lawrence and Botte. 


\section{Ethics approval and consent to participate}

As stated in the Methods section of this paper, the study received ethical approval by the local ethics committee (Ethics Committee of the Munich University Hospital, LMU; \# 541-14). All patients gave written informed consent.

\section{Consent for publication}

Not applicable.

\section{Competing interests}

The authors declare that they have no competing interests.

\section{Publisher's Note}

Springer Nature remains neutral with regard to jurisdictional claims in published maps and institutional affiliations.

Received: 5 June 2017 Accepted: 4 December 2017

Published online: 16 December 2017

\section{References}

1. Stewart IM. Jones's fracture: fracture of base of fifth metatarsal. Clin Orthop. 1960;16:190-8

2. Torg JS, Balduini FC, Zelko RR, Pavlov H, Peff TC, Das M. Fractures of the base of the fifth metatarsal distal to the tuberosity. Classification and guidelines for non-surgical and surgical management. J Bone Joint Surg Am. 1984;66(2):209-14.

3. Lawrence $\mathrm{SJ}$, Botte MJ. Jones' fractures and related fractures of the proximal fifth metatarsal. Foot \& ankle. 1993;14(6):358-65.

4. Dameron T. Fractures of the proximal fifth metatarsal: selecting the best treatment option. The Journal of the American Academy of Orthopaedic Surgeons. 1995;3(2):110-4

5. Polzer H, Polzer S, Mutschler W, Prall WC. Acute fractures to the proximal fifth metatarsal bone: development of classification and treatment recommendations based on the current evidence. Injury. 2012:43(10):1626-32.

6. Richter M, Zech S, Geerling J, Frink M, Knobloch K, Krettek C. A new foot and ankle outcome score: questionnaire based, subjective, visual-analoguescale, validated and computerized. Foot Ankle Surg. 2006;12(4):191-9.

7. Stüber J, Zech S, Bay R, Qazzaz A, Richter M. Normative data of the visual analogue scale foot and ankle (VAS FA) for pathological conditions. Foot Ankle Surg. 2011;17:166-72.

8. Richter M, Zech S, Geerling J, Frink M, Knobloch K, Krettek C. A new foot and ankle outcome score: questionnaire based, subjective, visual-analoguescale, validated and computerized. Foot Ankle Surg. 2006;12:191-9.

9. Zenios M, Kim WY, Sampath J, Muddu BN. Functional treatment of acute metatarsal fractures: a prospective randomised comparison of management in a cast versus elasticated support bandage. Injury. 2005;36(7):832-5.

10. Schmoz S, Voelcker AL, Burchhardt H, Tezval M, Schleikis A, Stürmer KM, Sehmisch $\mathrm{S}$. Conservative therapy for metatarsal 5 basis fractures retrospective and prospective analysis. Sportverletzung Sportschaden Organ der Gesellschaft für Orthopädisch-Traumatologische Sportmedizin. 2014;28(4):211-7.

11. Clapper MF, O'Brien TJ, Lyons PM. Fractures of the fifth metatarsal. Analysis of a fracture registry. Clin Orthop Relat Res. 1995;315:238-41.

12. Wiener BD, Linder JF, Giattini JF. Treatment of fractures of the fifth metatarsal: a prospective study. Foot Ankle Int. 1997;18(5):267-9.

13. Gray AC, Rooney BP, Ingram R. A prospective comparison of two treatment options for tuberosity fractures of the proximal fifth metatarsal. Foot (Edinburgh, Scotland). 2008;18(3):156-8.

14. Shahid MK, Punwar S, Boulind C, Bannister G. Aircast walking boot and below-knee walking cast for avulsion fractures of the base of the fifth metatarsal: a comparative cohort study. Foot Ankle Int. 2013;34(1):75-9.

15. Akimau PI, Cawthron KL, Dakin WM, Chadwick C, Blundell CM, Davies MB. Symptomatic treatment or cast immobilisation for avulsion fractures of the base of the fifth metatarsal: a prospective, randomised, single-blinded noninferiority controlled trial. The bone \& joint journal. 2016;98-B(6):806-11.

16. Egol K, Walsh M, Rosenblatt K, Capla E, Koval KJ. Avulsion fractures of the fifth metatarsal base: a prospective outcome study. Foot Ankle Int. 2007; 28(5):581-3.
17. Tahririan MA, Momeni A, Moayednia A, Yousefi E. Designing a prognostic scoring system for predicting the outcomes of proximal fifth metatarsal fractures at 20 weeks. Iranian journal of medical sciences. 2015;40(2):104-9.

18. Van Aaken J, Berli MC, Noger M, Gambirasio R, Fritschy D. Symptomatic treatment of non-displaced avulsion and Jones fractures of the fifth metatarsal: a prospective study. Revue médicale suisse. 2007;3(120):1792-4.

19. Bigsby E, Halliday R, Middleton RG, Case R, Harries W. Functional outcome of fifth metatarsal fractures. Injury. 2014;45(12):2009-12. doi:10.1016/j.injury. 2014.06.010.

20. Roche AJ, Calder JDF. Treatment and return to sport following a Jones fracture of the fifth metatarsal: a systematic review. Knee Surg Sports Traumatol Arthrosc. 2013;21(6):1307-15

21. O'Malley M, DeSandis B, Allen A, Levitsky M, O'Malley Q, Williams R. Operative treatment of fifth metatarsal Jones fractures (zones II and III) in the NBA. Foot Ankle Int. 2016:37(5):488-500. doi:10.1177/1071100715625290.

22. Stewart IM. Jones\&apos;s fracture: fracture of base of fifth metatarsal. Clin Orthop. 1960;16:190-8.

23. Dameron TB. Fractures and anatomical variations of the proximal portion of the fifth metatarsal. J Bone Joint Surg Am. 1975;57:788-92.

24. Lawrence SJ, Botte MJ. Jones\&apos; fractures and related fractures of the proximal fifth metatarsal. Foot \&amp; ankle. 1993;14:358-65.

25. Roche AJ, Calder JDF. Treatment and return to sport following a Jones fracture of the fifth metatarsal: a systematic review. Knee Surg Sports Traumatol Arthrosc. 2013;21:1307-15.

26. Gösele A, Schulenburg J, Ochsner PE. Early functional treatment of a 5th metatarsal fracture using an orthopedic boot. Swiss surgery = Schweizer Chirurgie $=$ Chirurgie suisse $=$ Chirurgia svizzera. 1997;3(2):81-4.

27. Stüber J, Zech S, Bay R, Qazzaz A, Richter M. Normative data of the visual analogue scale foot and ankle (VAS FA) for pathological conditions. Foot Ankle Surg. 2011;17(3):166-72.

28. Konkel KF, Menger AG, Retzlaff SA. Nonoperative treatment of fifth metatarsal fractures in an orthopaedic suburban private multispeciality practice. Foot \&amp; Ankle International. 2005;26:704-7.

29. Quill GE. Fractures of the proximal fifth metatarsal. The Orthopedic clinics of North America. 1995;26(2):353-61.

30. Rettig AC, Shelbourne KD, Wilckens J. The surgical treatment of symptomatic nonunions of the proximal (metaphyseal) fifth metatarsal in athletes. Am J Sports Med. 1992;20(1):50-4.

31. Rammelt S, Heineck J, Zwipp H. Metatarsal fractures. Injury. 2004;35(Suppl 2):SB77-86.

32. Zwitser EW, Breederveld RS. Fractures of the fifth metatarsal; diagnosis and treatment. Injury. 2010;41 (6):555-62.

33. Giordano AR, Fallat LM. Strength analysis of intraosseous wire fixation for avulsion fractures of the fifth metatarsal base. J Foot Ankle Surg. 2004;43(4):225-30.

34. SooHoo NF, Shuler M, Fleming LL, Society AOFaA. Evaluation of the validity of the AOFAS clinical rating systems by correlation to the SF-36. Foot \&amp; Ankle International. 2003:24:50-5.

35. Zarzaur BL, Kozar RA, Fabian TC, Coimbra R. A survey of American Association for the Surgery of Trauma member practices in the management of blunt splenic injury. J Trauma. 2011;70:1026-31.

36. Baumbach SF, Domaszewski F, Wyen H, Kalcher K, Mutschler W, Kanz K-G. Evaluation of the current treatment concepts in Germany, Austria and Switzerland for acute traumatic lesions to the prepatellar and olecranon bursa. Injury. 2013;44:1423-7.

37. Mehlhorn AT, Zwingmann J, Hirschmüller A, Südkamp NP, Schmal H. Radiographic classification for fractures of the fifth metatarsal base. Skelet Radiol. 2014;43(4):467-74.

38. Lareau CR, Hsu AR, Anderson RB. Return to play in National Football League Players after Operative Jones Fracture Treatment. Foot \&amp; Ankle International. 2016:37:8-16.

39. Lee K-t, Park Y-u, Jegal H, Park JW, Choi JP, Kim J-s. Prognostic classification of fifth metatarsal stress fracture using plantar gap. Foot Ankle Int. 2013;34:691-6.

40. Japjec M, Starešinić M, Starjački M, Žgaljardić I, Štivičić J, Šebečić B. Treatment of proximal fifth metatarsal bone fractures in athletes. Injury. 2015;46(Suppl 6): S134-6. doi:10.1016/j.injury.2015.10.052. 